\title{
Optimization of Medium Composition and Cultural Conditions for Enhanced Endoxylanase Production from Aspergillus fumigatus SKF-4 using Response Surface Methodology
}

\author{
Dolmani Amat ${ }^{1,2 *}$ and Livleen Shukla ${ }^{1}$ \\ ${ }^{1}$ ICAR- Indian Agricultural Research Institute, Division of Microbiology, New Delhi, India \\ ${ }^{2}$ ICAR-Indian Institute of Soil Science, Nabibagh, Berasia Road, Bhopal, India \\ *Corresponding author
}

\section{A B S T R A C T}

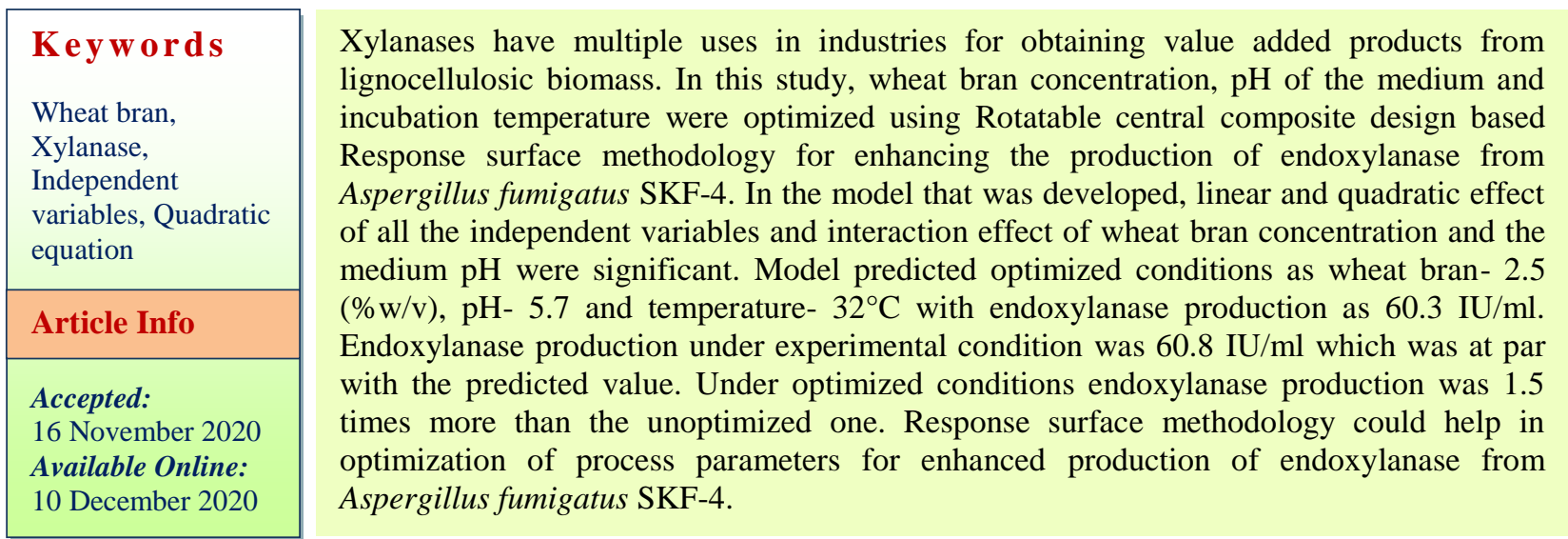

\section{Introduction}

Lignocellulosic materials (LCM) as source of organic residue are available in huge quantity in the world with a production of two billons tons annually (da Silva et al., 2012). Lignocelluloses are made up of cellulose (30$50 \%)$, hemicellulose (20-40\%) and lignin (1525\%) (Otieno and Ahring, 2012). Cellulose is the most abundant source of organic carbon in the world and hemicelluloses is next to it of which xylan is a major component. Xylan, a heteropolymer made up of $\beta-1,4$ linked xylopyranose units and may be further substituted by arabinoses, glucouronic acid, acetyl group and ferulic acid in varying proportion depending upon the source. Xylan can be converted to various value added products like biofuel, xylitol, xylose and xylooligosaccharides using xylanases and other debranching enzymes like arabinase, glucouronidnases, esterases.

Xylanases or endoxylanases (1,4-?-D-xylan xylanohydrolase, E.C. 3.2.1.8) are produced by various microorganisms like fungi, 
bacteria, actinomycetes and yeasts. Among these microorganisms fungi have been exploited the most as they produce highest titer of these enzymes which are secreted into the medium thus requiring less downstream processing. They can also be grown on cheap and readily available substrates like lignocellulosic biomasses. Cost of xylanases is an important factor that is to be considered for its industrial production. Hence there is need to minimize the cost of enzyme by using a potent microorganism, cheap substrates and different approaches for optimization of medium components. One variable at a time (OVAT) approach for selection and optimization of medium component for enhanced xylanase production is a traditional technique which involves changing a particular variable keeping all other at constant level. This approach has several shortcomings like, it is tedius as it requires large no. of experiments, does not help in the determination of optimum concentration of variables; also it misses the interaction between the variables that often do occur ( $\mathrm{Li}$ et al., 2006). Hence, recent statistical techniques like Plackett Burman Design (PBD) and Response Surface Methodology are common statistical method for optimizing the process variables.

Response surface methodology (RSM) comprises a series of statistical experimental designs which helps in identification of individual and interactive effect of independent variables and for finding out the optimum conditions in a multivariable system in a efficient way (Houng et al., 1989).

Response surface methodology has been used as a successful statistical tool for optimization of medium compositions in a fermentation process for enzyme production (Dobrev et al., 2007, Senthilkumar et al., 2005, Kim et al., 2007).
Literature survey revealed scanty information regarding the optimization of medium components for enhanced endoxylanase production with the help of response surface methodology from Aspergillus fumigatus. This paper aimed at determining the optimum levels of wheat bran concentration, medium $\mathrm{pH}$ and incubation temperature for enhanced endoxylanase production from Aspergillus fumigatus SKF-4 using Rotatable Central Composite Design (RCCD) based Response Surface Methodology (RSM).

\section{Materials and Methods}

\section{Microorganism}

Aspergillus fumigatus SKF-4 isolated from degraded corn cob was used in this study (Amat et al., 2016) and it was maintained on PDA (Potato Dextrose Agar) slants at $4^{\circ} \mathrm{C}$ until further use with regular subculturing.

\section{Production and extraction of endoxylanase}

The production of endoxylanase was carried out in the modified minimal medium (Reese and Mandel, 1963) containing (gram per liter) $\mathrm{KH}_{2} \mathrm{PO}_{4} 2.0, \mathrm{MgSO}_{4} .7 \mathrm{H}_{2} \mathrm{O} 0.3, \mathrm{CaCl}_{2} .2 \mathrm{H}_{2} \mathrm{O}$ $0.3, \quad \mathrm{FeSO}_{4} .7 \quad \mathrm{H}_{2} \mathrm{O} \quad 0.005, \quad \mathrm{MnSO}_{4} . \quad \mathrm{H}_{2} \mathrm{O}$ $0.0016, \mathrm{CoCl}_{2}$. $6 \mathrm{H}_{2} \mathrm{O} 0.002, \mathrm{ZnSO}_{4} .7 \mathrm{H}_{2} \mathrm{O}$ 0.0014 , wheat bran 10.0, proteose peptone 5.0 and $\mathrm{pH}$ 5.0. The optimization studies were carried out by changing the concentration of wheat bran, $\mathrm{pH}$ and incubation temperature as per the experimental design. For optimization, $100 \mathrm{ml}$ Erlenmeyer flask containing $25 \mathrm{ml}$ of the medium was used. Each flask was inoculated with $1 \mathrm{ml}$ of spore suspension containing $10^{7}$ spores prepared from 5 days old slant of Aspergillus fumigatus SKF-4. The flasks were incubated at $30{ }^{\circ} \mathrm{C}$ under static condition for 6 days. After incubation, fermentation broth was filtered and the filtrate was used as crude enzyme for estimation of endoxylanase activity. 


\section{Enzyme assays}

Endo- $\beta-1,4$-xylanase in crude extract was estimated using beechwood xylan as substrate (Ghose and Bisaria, 1987). Reducing sugars released were measured by DNSA method (Miller, 1959). One enzyme unit of endoxylanase was expressed as $1 \mu \mathrm{mol}$ xylose formed per milliliter of culture filtrate per min during hydrolysis under standard assay condition.

Optimization of process variables for enhanced endoxylanase production using rotatable central composite design based response surface methodology

Based on results of "one variable at a time" approach studied earlier (Amat et al., 2016) for endoxylanase production by Aspergillus fumigatus SKF-4, three important independent variables i.e. wheat bran, $\mathrm{pH}$ and temperature were selected for optimization by response surface methodology with rotatable central composite design (RCCD). Five different coded levels $(-\alpha,-1,0,+1,+\alpha)$ of each variables were taken for optimization study and the design was formulated with the help of experimental design module of Design Expert software version 10 (Stat Ease Inc., Minneapolis, USA). Twenty experimental runs were designed which includes eight factorial points, six axial points and six replicates at the centre point. Table 1 shows the ranges and levels of independent variables i.e. (A) wheat bran, (B) $\mathrm{pH}$ and (C) temperature selected for the current study in coded and decoded values.

Experimental Design for the study of optimization has been given in Table 2 where values of variables at various levels along with their respective responses have been presented. Data obtained from the response surface methodology(RSM) were subjected to analysis of variance (ANOVA) to get the regression coefficients, prediction equations and case statistics using Design Expert software. The results obtained from RSM were fitted using a polynomial quadratic equation (Eq.1) to describe the mathematical relation between the variables and the response.

$\mathrm{Y}=\beta_{0}+\beta_{1} \mathrm{~A}+\beta_{2} \mathrm{~B}+\beta_{3} \mathrm{C}+\beta_{12} \mathrm{AB}+\beta_{23} \mathrm{BC}+$ $\beta_{13} A C+\beta_{11} A^{2}+\beta_{22} B^{2}+\beta_{33} C^{2}$

Where $\mathrm{Y}$ represents the predicted response, $\beta 0$ is the constant; $\beta_{1}, \beta_{2}, \beta_{3}$ are linear coefficients; $\beta 12, \beta_{23}, \beta_{13}$ are interaction coefficients and $\beta_{11}, \beta_{22}, \beta_{33}$ are quadratic coefficients (Singh et al., 2014). The model validation was carried out for all the variables within the design space. Quality of fit of the polynomial model equation was expressed by the co-efficient of determination $\left(\mathrm{R}^{2}\right)$; statistical significance of the model was determined by application of Fisher's F-test and level of significance was given by $\mathrm{p}$ value. Contour plots and corresponding response surface plots were drawn using Design Expert software to study the effect of independent variable and their interactions on response (endoxylanase production). An experiment was carried out to confirm the predicted optimum response using the selected optimum values of three variables.

\section{Results and Discussion}

Use of beechwood xylan as substrate for endoxylanase production is highly expensive, so alternate cheap and easily available substrates mainly lignocellulosic in nature like wheat bran was used for the present study. Wheat bran, $\mathrm{pH}$ and temperature were taken for optimization using rotatable central composite design based response surface methodology. These variables were tested at five levels. The experimental detail with respect to their coded and actual form is given in Table 1. A total of 20 experimental runs 
having different combination of wheat bran, $\mathrm{pH}$ and temperature were carried out. Experimental design with actual and predicted response has been given in Table 2 which showed that there existed a wide variation in the responses ( $\beta$-endoxylanase) in different experimental runs depending upon the levels of three independent variables in the medium, so there was need to optimize these variables for maximum production of $\beta$-endoxylanase.

Responses ( $\beta$-endoxylanase) given in Table 2 are the average of two replicates. Maximum production of $\beta$-endoxylanase $(62.3 \mathrm{IU} / \mathrm{ml})$ was observed in run no. 11 whereas minimum level of production $(44.9 \mathrm{IU} / \mathrm{ml})$ was observed in run no. 8. Runs $1,4,5,7,9,11$ were the centre point which were taken for estimation of the error in the experimental design. The overall mean and standard deviation of the runs of the experimental design were 52.72 $\mathrm{IU} / \mathrm{ml}$ and 2.18 respectively.

Multiple regression analysis was carried out on the experimental results (Table 2) to get a second order polynomial equation (Eq. 2) which could explain the $\beta$-endoxylanase production.

Endoxylanase $=+57.98+2.72 \times \mathrm{A}+1.54 \mathrm{x} \mathrm{B}$ $+2.02 \times \mathrm{C}+2.24 \times \mathrm{AB}+0.46 \times \mathrm{AC}-0.44 \mathrm{x}$ $\mathrm{BC}-2.2 \mathrm{xA}^{2}-2.61 \mathrm{xB}^{2}-2.89 \mathrm{xC}^{2}$

Where A, B, C are coded value of the variables i.e. wheat bran, $\mathrm{pH}$ and temperature respectively.

On observation of Eq. 2, it was found that effect of one factor is being represented by that factor with its co-efficient. Further, for two factors, it has been seen that, co-efficients with two factors represents interaction among the two factors while co-efficients with second order term shows the quadratic effect of the variables. Furthermore, two types of effect for endoxylanase production can be observed from the equation i.e. synergestic effect where a positive sign is present before the terms where as antagonistic effect showed by negative sign in front of the terms. The statistical significance of the model was carried out by Fisher's test for analysis of variance (ANOVA). Results of ANOVA of the response surface quadratic model of different variables for $\beta$-endoxylanase production has been presented in Table 3 .

Model of endoxylanase production as a function of (A) wheat bran, (B) $\mathrm{pH}$, and (C) temperature had probability value ( $\mathrm{p}$-value) 0.0004. Goodness of fit of the model was tested by $\mathrm{R} 2$ value. In this experiment $\mathrm{R}^{2}$ value was 0.9 and the coefficient of variation (CV) value was $4.13 \%$. From the Table 3 it can also be found that based on p-value (pvalue < 0.05 ) model terms i.e. $\mathrm{A}, \mathrm{B}, \mathrm{C}, \mathrm{AB}$, A2, B2, C2 were found to be significant and $\mathrm{AC}, \mathrm{BC}$ were found non-significant. Three variables under study i.e. wheat bran, $\mathrm{pH}$, and temperature showed negative quadratic effect on endoxylanase production at various levels of significance. The lack of fit test in this study was found to be non-significant (pvalue $>0.05$ ) and adequate precision value which indicates signal to noise ratio was 8.5.

The adjusted $\mathrm{R}^{2}$ and predicted $\mathrm{R}^{2}$ value were 0.83 and 0.74 respectively which were close to each other. The contour plot and corresponding response surface plots described by second-order polynomial equation were generated in order to investigate the interaction among the variables and optimal level of variables for xylanase production (Fig. 1a- 1f). Each figure represents the effect of two variables on production of endoxylanase while the third variable was held at middle level. The statistically optimal values of variables are obtained when moving along the major and minor axis of the contour at the centre point yields maximum endoxylanase production. 
Fig. 1a and 1f represents the response surface plot and corresponding contour plot depicting the effect of medium $\mathrm{pH}$ and wheat bran concentration simultaneously on endoxylanase production at the middle level of incubation temperature $\left(30^{\circ} \mathrm{C}\right)$. It was found that at low $\mathrm{pH}(4.5)$ when concentration of wheat bran was varied from $0.7 \%(\mathrm{w} / \mathrm{v})$ $2.5 \%(\mathrm{w} / \mathrm{v})$, the endoxylanase production was slightly affected and it was observed in the range of $52.8 \mathrm{IU} / \mathrm{ml}-56.0 \mathrm{IU} / \mathrm{ml}$ respectively. Increase in $\mathrm{pH}$ from 4.5 to 5.5 simultaneously increasing the wheat bran concentration from $0.7 \%(\mathrm{w} / \mathrm{v})-2.5 \%(\mathrm{w} / \mathrm{v})$ resulted in higher endoxylanase production from $52.1 \mathrm{IU} / \mathrm{ml}$ $59.80 \mathrm{IU} / \mathrm{ml}$ respectively which was found to be higher as compared to the enzyme produced at $\mathrm{pH}$ 4.5. From the Fig. 1a and 1f maximum production of endoxylanase (59.9 $\mathrm{IU} / \mathrm{ml}$ ) was observed in the wheat bran concentration 2.4- 2.5\% (w/v) and $\mathrm{pH}$ 5.6-5.8. Similarly Fig. 1c and 1d depicts effect of wheat bran concentration and incubation temperature on endoxylanase production while $\mathrm{pH}$ of the medium was kept at middle level (5.0). At low wheat bran concentration $(1 \% \mathrm{w} / \mathrm{v})$, there was gradual increase in endoxylanase production from $50.7 \mathrm{IU} / \mathrm{ml}$ at $25^{\circ} \mathrm{C}$ to $54.1 \mathrm{IU} / \mathrm{ml}$ at $35^{\circ} \mathrm{C}$ whereas increase was more significant at high wheat bran concentration $(2.2 \% \mathrm{w} / \mathrm{v})$ from $53.6 \mathrm{IU} / \mathrm{ml}$ at $25^{\circ} \mathrm{C}$ to $58.3 \mathrm{IU} / \mathrm{ml} 35^{\circ} \mathrm{C}$. From Fig. $1 \mathrm{c}$ and 1d, optimum temperature and wheat bran concentration for maximum endoxylanase production $(59.3 \mathrm{IU} / \mathrm{ml})$ was observed in the range $2.1-2.3 \%(\mathrm{w} / \mathrm{v})$ to $31.5^{\circ} \mathrm{C}-32.5^{\circ} \mathrm{C}$ respectively.

Next, Fig. 1e and 1f depicts the effect of $\mathrm{pH}$ and incubation temperature on endoxylanase production while wheat bran concentration was kept at middle level $(1.6 \% \mathrm{w} / \mathrm{v})$. It was observed that at low temperature $\left(27^{\circ} \mathrm{C}\right)$ increase in $\mathrm{pH}$ from 4.0- 6.0 resulted in increase in endoxylanase production from $51.3 \mathrm{IU} / \mathrm{ml}$ to $54.9 \mathrm{IU} / \mathrm{ml}$ respectively which was more than when $\mathrm{pH}$ was increased 4.06.0 at high temperature $\left(33^{\circ} \mathrm{C}\right)$ resulting in endoxylanase production from $54.3 \mathrm{IU} / \mathrm{ml}$ to $56.7 \mathrm{IU} / \mathrm{ml}$ respectively. From Fig. 1e and 1f, optimal region of $\mathrm{pH}$ and temperature for maximum endoxylanase production (58.5 $\mathrm{IU} / \mathrm{ml}$ ) was found to be between 5.1-5.4 and $31^{\circ} \mathrm{C}-32.4^{\circ} \mathrm{C}$ respectively.

\section{Optimization and validation of model equation}

Process variables were numerically optimized using Design-Expert® software version 10 for $\beta$-endoxylanase production (Table 4 ). In the validation or confirmation of the model under the optimization step in rotatable central composite design, the variables were set according to specific requirements of the model. For the maximum yield of endoxylanase production, the goal of the response was set as 'maximize' and the level of variables i.e. wheat bran, $\mathrm{pH}$ and temperature were set as 'in range', means from -1 to +1 level. The software provided two solutions, one with medium comprising wheat bran $-2.5 \%(\mathrm{w} / \mathrm{v}), \mathrm{pH}-5.7$ and temperature- $32^{\circ} \mathrm{C}$ predicted maximum endoxylanase production of $60.3 \mathrm{IU} / \mathrm{ml}$ and this solution had the maximum desirability of 0.9 and was taken for validation of the model. The model was validated by carrying out production of endoxylanase under optimized conditions and it was found that endoxylanase production of $60.8 \mathrm{IU} / \mathrm{ml}$ was achieved which was close to the predicted value of 60.3 $\mathrm{IU} / \mathrm{ml}$.

The cost of endoxylanase is an important factor for its industrial applications. So to make the enzyme cost effective, there is need to use cheap substrates like lignocellulosic biomass based agri-residue, optimization of medium components (C-source, $\mathrm{N}$ - sources) and cultural conditions using different statistical approaches. Keeping these things 
into view, in this study, instead of using pure substrate like beechwood xylan, wheat bran, a cheap lignocellulosic substrate as carbon source was used. Along with wheat bran, $\mathrm{pH}$ and temperature which are important cultural conditions affecting the enzyme production were studied. One variable at a time (OVAT) approach for selection and optimization of medium component for enhanced xylanase production involves changing a particular variable keeping all other at constant level. This approach does not help in the determination of optimum concentration of variables; also it misses the interaction between the variables that often do occur $(\mathrm{Li}$ et al., 2006). Hence, recent statistical techniques like Response Surface Methodology (RSM) are commonly used for optimization of process variables.

Table.1 Minimum and maximum levels of independent variables used for rotatable central composite design matrix

\begin{tabular}{|l|l|l|l|l|l|l|}
\hline $\begin{array}{l}\text { Independent } \\
\text { Variables }\end{array}$ & Symbols & & & Coded levels & & \\
\hline & & $\boldsymbol{- \alpha}$ & $\mathbf{- 1}$ & $\mathbf{0}$ & $+\boldsymbol{\alpha}$ & $\mathbf{+ 1}$ \\
\hline Wheat bran $(\boldsymbol{\%} \mathbf{w} / \mathbf{v})$ & $\mathrm{A}$ & 0.1 & 0.7 & 1.6 & 2.5 & 3.1 \\
\hline pH & $\mathrm{B}$ & 3.3 & 4 & 5 & 6 & 6.7 \\
\hline Temperature $\left({ }^{\circ} \mathbf{C}\right)$ & $\mathrm{C}$ & 21.5 & 25 & 30 & 35 & 38.4 \\
\hline
\end{tabular}

Table.2 Rotatable Central Composite Design experimental design matrix and the respective endoxylanase activity by Aspergillus fumigatus SKF-4

\begin{tabular}{|c|c|c|c|c|c|}
\hline \multirow[t]{3}{*}{ Run } & \multicolumn{3}{|c|}{ Independent variable } & \multirow{2}{*}{\multicolumn{2}{|c|}{$\begin{array}{c}\text { Response(IU/ml) } \\
\text { ß-endoxylanase }\end{array}$}} \\
\hline & \multirow[t]{2}{*}{$\begin{array}{c}\text { A: Wheat bran } \\
(\% \mathrm{w} / \mathrm{v})\end{array}$} & \multirow[t]{2}{*}{ B: pH } & \multirow[t]{2}{*}{$\begin{array}{c}\text { C: Temperature } \\
\left({ }^{\circ} \mathrm{C}\right)\end{array}$} & & \\
\hline & & & & Actual & Predicted \\
\hline 1 & 1.6 & 5 & 30 & 57.7 & 58.0 \\
\hline 2 & 0.7 & 4 & 25 & 45.3 & 46.3 \\
\hline 3 & 1.6 & 6.7 & 30 & 52.3 & 53.2 \\
\hline 4 & 1.6 & 5 & 30 & 54.3 & 58.0 \\
\hline 5 & 1.6 & 5 & 30 & 58.7 & 58.0 \\
\hline 6 & 3.1 & 5 & 30 & 57.2 & 56.3 \\
\hline 7 & 1.6 & 5 & 30 & 58.5 & 58.0 \\
\hline 8 & 2.5 & 4 & 25 & 44.9 & 46.3 \\
\hline 9 & 1.6 & 5 & 30 & 56.2 & 58.0 \\
\hline 10 & 2.5 & 4 & 35 & 51.3 & 52.1 \\
\hline 11 & 1.6 & 5 & 30 & 62.3 & 58.0 \\
\hline 12 & 1.6 & 3.3 & 30 & 50.0 & 48.0 \\
\hline 13 & 2.5 & 6 & 25 & 54.7 & 54.7 \\
\hline 14 & 2.5 & 6 & 35 & 59.0 & 58.8 \\
\hline 15 & 0.7 & 4 & 35 & 49.5 & 50.2 \\
\hline 16 & 1.6 & 5 & 21.6 & 47.4 & 46.4 \\
\hline 17 & 0.1 & 5 & 30 & 47.4 & 47.2 \\
\hline 18 & 0.7 & 6 & 25 & 45.8 & 45.7 \\
\hline 19 & 0.7 & 6 & 35 & 48.6 & 48.0 \\
\hline 20 & 1.6 & 5 & 38.4 & 53.3 & 53.2 \\
\hline
\end{tabular}


Table.3 Analysis of variance (ANOVA) for response surface quadratic model of different factors for $\beta$-endoxylanase production

\begin{tabular}{|c|c|c|c|c|c|}
\hline Source & Sum of squares & Degree of freedom & Mean square & $\begin{array}{l}F- \\
\text { Value }\end{array}$ & $p$-Value $($ Prob $>F)$ \\
\hline Model & 474.38 & 9 & 52.71 & 11.13 & 0.0004 \\
\hline A-Wheat Bran & 101.23 & 1 & 101.23 & 21.37 & 0.0009 \\
\hline B- pH & 32.19 & 1 & 32.19 & 6.80 & 0.0262 \\
\hline C- Temperature & 55.87 & 1 & 55.87 & 11.79 & 0.0064 \\
\hline AB & 40.05 & 1 & 40.05 & 8.45 & 0.0156 \\
\hline $\mathbf{A C}$ & 1.71 & 1 & 1.71 & 0.36 & 0.5612 \\
\hline BC & 1.53 & 1 & 1.53 & 0.32 & 0.5822 \\
\hline$A^{2}$ & 69.94 & 1 & 69.94 & 14.76 & 0.0033 \\
\hline $\mathbf{B}^{2}$ & 98.14 & 1 & 98.14 & 20.72 & 0.0011 \\
\hline $\mathrm{C}^{2}$ & 120.57 & 1 & 120.57 & 25.45 & 0.0005 \\
\hline Residual & 47.38 & 10 & 4.74 & & \\
\hline Lack of Fit & 11.14 & 5 & 2.23 & 0.31 & 0.8893 \\
\hline Pure Error & 36.23 & 5 & 7.25 & & \\
\hline Total & 521.75 & 19 & & & \\
\hline Mean & 52.72 & & $\mathbf{R}^{2}$ & 0.90 & \\
\hline $\mathbf{S D}^{\mathbf{a}}$ & 2.18 & & Adjusted $\mathbf{R}^{2}$ & 0.83 & \\
\hline $\mathrm{CV} \%{ }^{\mathrm{b}}$ & 4.13 & & Predicted $\mathbf{R}^{2}$ & 0.74 & \\
\hline
\end{tabular}

${ }^{\mathrm{a}}$ Standard Deviation, ${ }^{\mathrm{b}}$ Co-efficent of Variation

Table.4 Optimum value of variables for endoxylanse production by Aspergillus fumigatus SKF-4

\begin{tabular}{|c|c|c|c|}
\hline Variables & Goal & Optimum level & Desirability \\
\hline Wheat bran $(\% \mathrm{w} / \mathrm{v})$ & In range & 2.5 & 0.9 \\
\hline pH & In range & 5.7 & -do- \\
\hline Temperature $\left({ }^{\circ} \mathbf{C}\right)$ & In range & 31.9 & -do- \\
\hline Response & Goal & Predicted value & Observed value \\
\hline Endoxylanase (IU/ml) & Maximize & 60.8 & 60.3 \\
\hline
\end{tabular}

* International Unit/milliliter

Fig.1 (a) Contour plot of combined effect of wheat bran and $\mathrm{pH}$ on endoxylanase (IU/ml) production by Aspergillus fumigatus SKF-4 with constant temperature

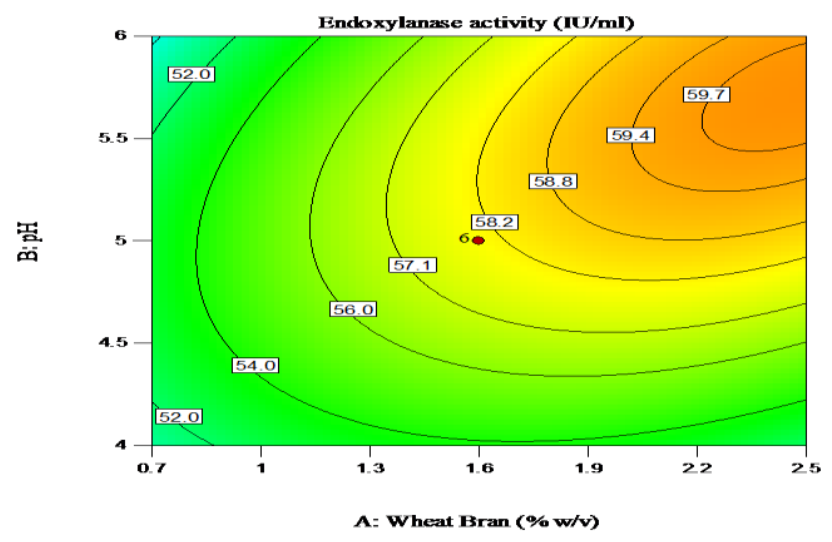


Fig.1 (b) Response surface plot of combined effect of wheat bran and $\mathrm{pH}$ on endoxylanase (IU/ml) production by Aspergillus fumigatus SKF-4 with constant temperature

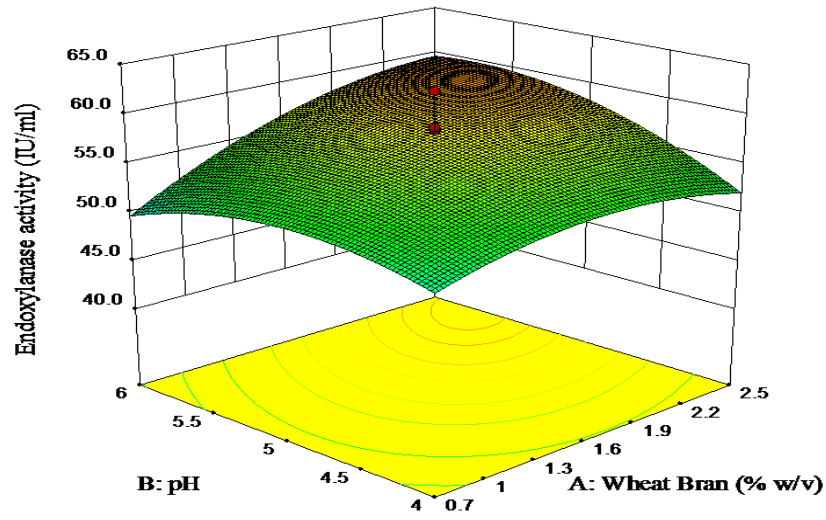

Fig.1 (c) Contour plot of combined effect of wheat bran and temperature on endoxylanase (IU/ml) production by Aspergillus fumigatus SKF-4 with constant $\mathrm{pH}$

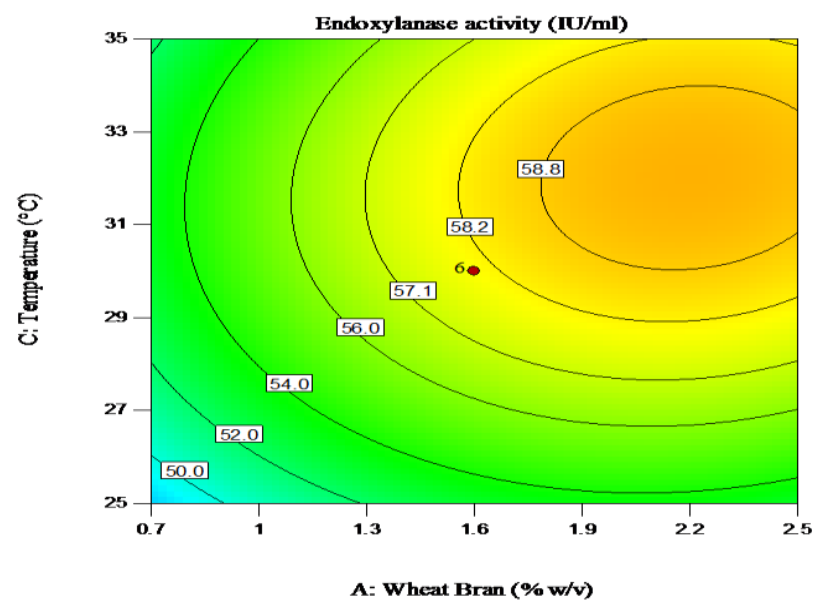

Fig.1 (d) Response surface plot of combined effect of wheat bran and temperature on endoxylanase (IU/ml) production by Aspergillus fumigatus SKF-4 with constant $\mathrm{pH}$

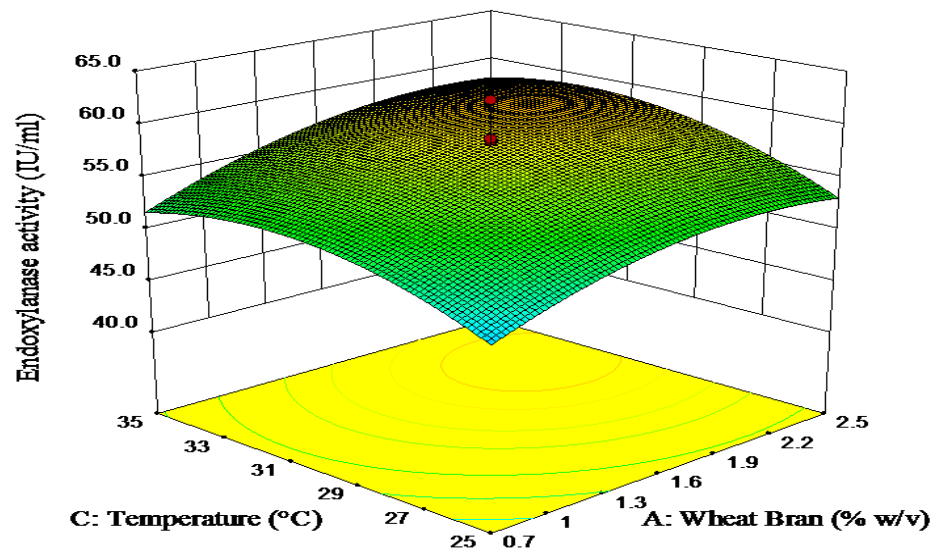


Fig.1 (e) Contour plot of combined effect of $\mathrm{pH}$ and temperature on endoxylanase (IU/ml) production by Aspergillus fumigatus SKF-4 with constant wheat bran concentration

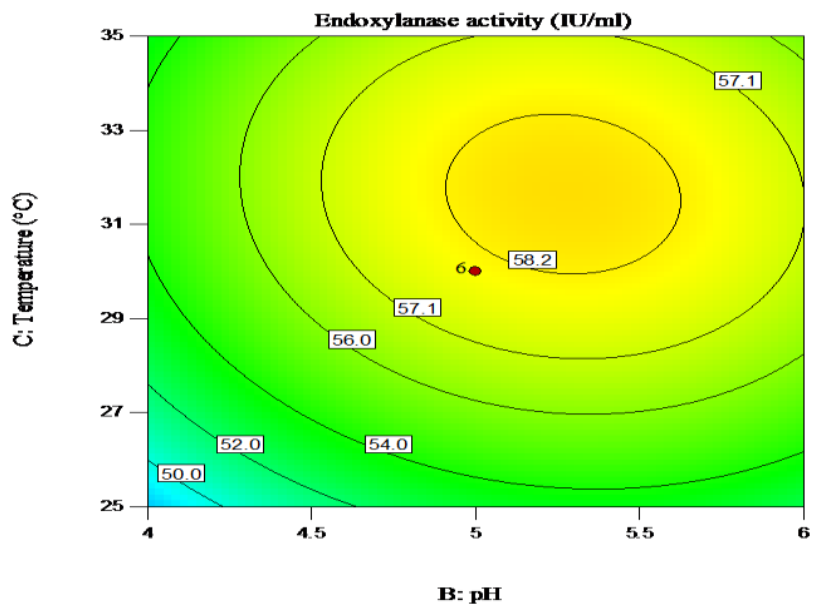

Fig.1 (f) Response surface plot of combined effect of $\mathrm{pH}$ and temperature on endoxylanase (IU/ml) production by Aspergillus fumigatus SKF-4 with constant wheat bran concentration

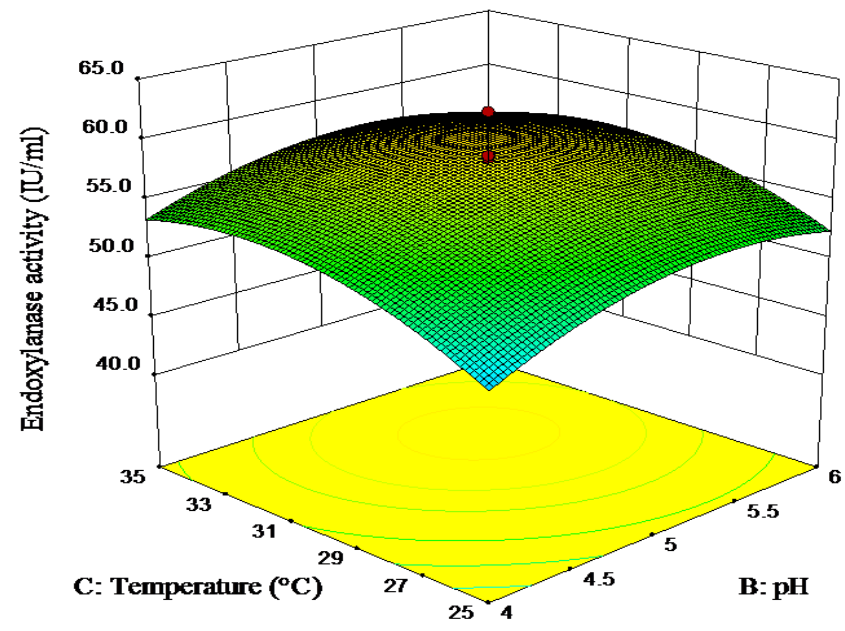

Wheat bran, $\mathrm{pH}$ and temperature were optimized using rotatable central composite design based response surface methodology. RSM is a collection of statistical and mathematical techniques, normally used for modeling and analyzing problems in which several variables influencing the response of interest may be tested and aim is to optimize the response (Myers and Montgomery, 2009). Rotatable Central Composite Design (RCCD) has been the design of choice for optimization studies in biochemical processes due to its obvious advantages of ratability and the ability to analyze the interaction effects over mixture design (Ferreira et al., 2009).

Ranges of the three variables were decided for RCCD design based on one factor at a time approach. Wheat bran concentration range was determined by taking 0.1 to $3 \%(\mathrm{w} / \mathrm{v})$ wheat bran in Reese minimal medium. In the range of wheat bran concentration from $0.7 \%$ $2.5 \%$, higher production of endoxylanase was observed (date not shown). Hence this range was selected for RCCD design. Similar range i.e. 1 to $2 \%(\mathrm{w} / \mathrm{v})$ of wheat bran concentration 
was selected by Saha and Ghosh (2014) for optimization using RCCD based response surface methodology.

Similarly for the RCCD design, $\mathrm{pH}$ range 4.06.0 and temperature of $25-35^{\circ} \mathrm{C}$ was selected, as in this range higher production of endoxylanase was observed (date not shown). Saha and Ghosh (2014) also selected $\mathrm{pH}$ range 3.0-6.0 for optimization by using RCCD by response surface methodology. Li et al (2007) selected $25-35^{\circ} \mathrm{C}$ for optimization of temperature using central composite design. From Table 3, it was found that model of endoxylanase production as a function of (A) wheat bran, (B) $\mathrm{pH}$ and (C) temperature was found to be significant ( $p$-value< 0.05 ). Goodness of fit of the model is tested by $R^{2}$ (co-efficient of determination) value. $\mathrm{R}^{2}$ value generally exist in the range of $0-1.0$. The closer the value to 1.0 , the more fit is the experimental data to the model (Singh et al., 2014). In this study $\mathrm{R}^{2}$ value of 0.9 indicated that $90 \%$ variability of response $(\beta$ endoxylanase) is attributed to the independent variables and only $10 \%$ variation could not be explained by the model. The coefficient of variation (CV) indicates the degree of precision with which the treatments are compared and the higher the value of $\mathrm{CV}$, the lower the reliability of the experiment performed. The lower value of the co-efficient of variation $(\mathrm{CV} \%=4.13)$ in this case showed that the experiments conducted were precise and reliable. The predicted $R^{2}$ and adjusted $R^{2}$ value were close to each other which indicate that actual value and predicted values are close to each other in this experiment. From the Table 3, it can also be found that based on $\mathrm{p}$ - value ( $\mathrm{p}$-value<0.05) model terms i.e. $\mathrm{A}, \mathrm{B}$, $\mathrm{C}, \mathrm{AB}, \mathrm{A}^{2}, \mathrm{~B}^{2}, \mathrm{C}^{2}$ were found to be significant and $\mathrm{AC}, \mathrm{BC}$ were found non-significant. Wheat bran, $\mathrm{pH}$ and temperature had significant ( $p$-value <0.05) linear effect on endoxylanase production with trend, wheat bran > $\mathrm{pH}>$ temperature. Wheat bran (A) showed significant interaction with medium $\mathrm{pH}$ (p-value <0.05), however, interaction between wheat bran and temperature and between $\mathrm{pH}$ and temperature was not significant ( $p$-value>0.05). All the three variables showed significant negative quadratic effect on endoxylanase production. Similar findings were reported by other researcher where Rotatable Central Composite Design (RCCD) was used to optimize the concentration of wheat bran, $\mathrm{NaNO}_{3}$, Tween-80 and Yeast extract in the fermentation medium for enhanced xylanase production from Aspergillus flavus DFR-6 in submerged cultivation and found that wheat bran showed significant linear effect and significant negative quadratic effect on endoxylanase production (Pal and Khanum, 2011). While using RCCD based response surface methodology for optimization of wheat bran, $\mathrm{pH}$ of the medium and temperature for enhanced endoxylanase production by Penicillum citrinum xym2, it was found that wheat bran, $\mathrm{pH}$ of the medium and temperature showed significant negative quadratic effect on endoxylanase production and wheat bran and $\mathrm{pH}$ of the medium had significant interaction and there was no significant interaction between $\mathrm{pH}$ of the medium and incubation temperature on endoxylanase production (Saha and Ghosh, 2014). Optimization of different variables i.e. wheat bran, $\mathrm{pH}$ and cultivation time using central composite rotary design based Response surface methodology revealed that wheat bran and $\mathrm{pH}$ had significant negative quadratic effect, wheat bran and $\mathrm{pH}$ of the medium had significant linear effect on production of endoxylanase by Aspergillus awamori ZH-26 (Li et al., 2006). The lack of fit test in this study was found to be insignificant ( $p$-value> 0.05) which indicated the absence of block effect in the experiment. Adequate precision value indicates signal to noise ratio and a ratio greater than 4 is desirable. Hence in this model adequate 
precision value of 8.505 acknowledged an adequate signal.

Contour plot and corresponding response surface plots described by second-order polynomial equation were generated in order to investigate the interaction among the variables and optimal level of variables for xylanase production (Fig. 1a- 1f). From Fig. $1 \mathrm{a}$ and $1 \mathrm{~b}$, it can be observed that at fixed temperature, at both high and low $\mathrm{pH}$; increase in wheat bran concentration within the experimental region was beneficial for increasing the endoxylanase production. These results agree well with the report that wheat bran could effectively induce higher xylanase production by Streptomyces sp (Beg et al., 2000). Also the shape of the corresponding contour plots indicates whether the mutual interactions between the independent variables are significant or not. An elliptical nature of the contour plots indicates that the interactions between the independent variables are significant ( $\mathrm{Li}$ et al., 2007). In this case contour plot is elliptical hence by visual observation it can be observed that there was significant interactions between $\mathrm{pH}$ and wheat bran concentration. Similarly from Fig. 1c and 1d, it can be inferred that near optimum wheat bran concentration, increase in temperature within the experimental range has positive effect on endoxylanase production and Fig. 1e and 1f depict that at optimum $\mathrm{pH}$ and temperature wheat bran will have positive effect in endoxylanase production indicating organism can utilize the substrate more efficiently for production of endoxylanase under optimum $\mathrm{pH}$ and temperature.

In the optimization and validation step, the experimental response (endoxylanase production) of $60.8 \mathrm{IU} / \mathrm{ml}$ was in close agreement with the predicted response of $60.3 \mathrm{IU} / \mathrm{ml}$, hence the model was successfully validated and therefore the model developed was reliable for predicting the optimal conditions for variables influencing endoxylanase production by Aspergillus fumigatus SKF-4. The optimization of process variables for endoxylanase production using RCCD based Response surface methodology resulted in 1.5 times increase in endoxylanase production from Aspergillus fumigatus SKF-4 than the unoptimized one. These results from the study also indicate that at optimum temperature and $\mathrm{pH}$, there was increase in endoxylanase production which could be due to better growth of the microorganism and production of enzyme for utilization of substrate and also accounted for the fact that enzyme involved in substrate degradation generally inducible in nature and are produced in presence of the substrate (Schlegel, 1989). Similar optimal temperature and $\mathrm{pH}$ were obtained by central composite design as $32.5^{\circ} \mathrm{C}$ and 5.5 respectively for enhanced production of endoxylanase from Aspergillus niger ITCC 7678 (Singh et al., 2013). The endoxylanase produced by Aspergillus fumigatus SKF-4 was four times more than Penicillium oxalicum $\mathrm{ZH}-30$ (Li et al., 2007) using the RSM optimized medium containing wheat bran.

\section{Acknowledgements}

The authors are thankful to Post Graduate School, ICAR-Indian Agricultural Research Institute (IARI) and Indian Council of Agricultural Research (ICAR) for providing financial help in conducting the research work.

\section{References}

Da Silva S.S., Chande, A.K., Wickramasinghe, S.R. and Domínguez, J.M.G. 2012. Fermentative Production of Value-Added Products from Lignocellulosic Biomass. J. Biomed. Biotechnol. 2012, 1-2. 
Otieno, D.O. and Ahring, B.K. 2012. A thermochemical pretreatment process to produce xylooligosaccharides (XOS), arabino oligosaccharides (AOS) and mannooligosaccharides (MOS) from lignocellulosic biomasses. Bioresour. Technol. 112, 285-292.

Li, Y., Lin, J., Meng, D., Lu, G. and Gu, Z. 2006. Effect of $\mathrm{pH}$, cultivation time and substrate concentration on the endoxylanase production by Aspergillus awamori $\mathrm{ZH}-26$ under submerged fermentation using Central Composite Rotary Design. Food Technol. Biotechnol. 44, 473477.

Houng, J.Y., Chen, K.C. and Hsu, W. H. 1989. Optimization of cultivation medium composition for isoamylase production. Appl. Microbiol. Biot. 31, 61-64.

Dobrev, G.T., Pishtiyski, I.G., Stanchev, V.S. and Mircheva, R. 2007. Optimization of nutrient medium containing agricultural wastes for xylanase production by Aspergillus niger $\mathrm{B} 03$ using optimal composite experimental design. Bioresour. Technol. 98, 26712678.

Senthilkumar, S.R., Ashok kumar, B., Chandra, Raj, K., Gunasekaran, P. 2005. Optimization of medium composition for alkali-stable xylanase production by Aspergillus fischeri Fxn 1 in solid-state fermentation using central composite rotary design. Bioresour. Technol. 96, 1380-1386.

Kim, Y,H., Kang, S.W., Lee, J.H. and Chang, H.L. 2007. High cell density fermentation of Saccharomyces cerevisiae JUL3 in fed batch culture for the production of b-Glucan. J. Ind. Eng. Chem. 13, 153-158.

Amat D, Shukla, L and Singh S. 2016. Bioprospecting of xylanolytic fungi isolated from degraded corn cobs for xylooligosaccharides production. Journal of Pure and Applied Microbiology 10: 2687-2696.

Ghose TK and Bisaria VS.1987. Measurement of hemicellulase activities part 1: xylanases. Pure Appl. Chem. 59, 1739-51.

Miller, G.L. 1959. Use of dinitrosalicyclic reagent for determination of reducing sugar. Anal. Chem. 31, 426-28.

Singh, A., Manju Yadav, A. and Bishnoi, N.R. 2013. Statistical screening and optimization of process variables for xylanase production utilizing alkalipretreated rice husk. Ann. Microbiol. 63, 353-61.

Myers, R. H., Montgomery, D.C. and Anderson-Cook, C.M. 2009. Response surface methodology: Process and product optimization using designed experiments. Wiley, New York. 821 pp.

Ferreira, S., Duarte, A.P., Ribeiro, M.H.L., Queiroz, J.A. and Domingues, F.C. 2009. Response surface optimization of enzymatic hydrolysis of Cistus ladanifer and Cistus striatus for bioethanol production. Biochem. Eng. J. 45, 192- 200.

Singh, S., Pranaw, K., Singh, B., Tiwari, R. and Nain, L. 2014. Production, optimization and evaluation of multicomponent holocellulase produced by Streptomyces sp. ssr-198. J. Taiwan Inst. Chem. Eng. 45, 237986.

Pal and Khanum, F. 2011. Identification and Optimization of Critical Medium Components Using Statistical Experimental Designs for Enhanced Production of Xylanase from Aspergillus flavus DFR-6. Food Technol. Biotechnol., 49, 228236

Saha, S.P. and Ghosh, S. 2014. Optimization of xylanase production by Penicillium 
citrinum xym2 and application in saccharification of agro-residues. Biocatal. Agric. Biotechnol 3, 188-196.

Beg, Q.K., Bhushan, B., Kapoor, M. and Hoondal, G.S. 2000. Production and characterization of thermostable xylanase and pectinase from Streptomyces sp. QG-11-3. J. Ind. Microbiol. Biotechnol. 24, 396-402.

Schlegel, H.G. 1989. The Metabolism of Microorganisms. In: Prave P, Faust U, Sitting W, Sukatsch DA (eds) Basic Biotechnology-A Student's Guide. VHC-Publishers, New York, pp 67-
101.

Li, Y., Cui, F., Liu, Z., Xu, Y. and Zhao, H. 2007. Improvement of xylanase production by Penicillium oxalicum $\mathrm{ZH}-30$ using response surface methodology. Enzyme Microb. Technol. 40, 1381-88.

Reese ET and Mandel M. 1963. Enzymatic hydrolysis of cellulose and its derivatives. Methods in Carbohydrate Chemistry Vol. III, pp. 139-143. Whistler RL (Ed.). Academic Press, New York.

\section{How to cite this article:}

Dolmani Amat and Livleen Shukla. 2020. Optimization of Medium Composition and Cultural Conditions for Enhanced Endoxylanase Production from Aspergillus fumigatus SKF-4 using Response Surface Methodology. Int.J.Curr.Microbiol.App.Sci. 9(12): 2378-2390. doi: https://doi.org/10.20546/ijcmas.2020.912.283 